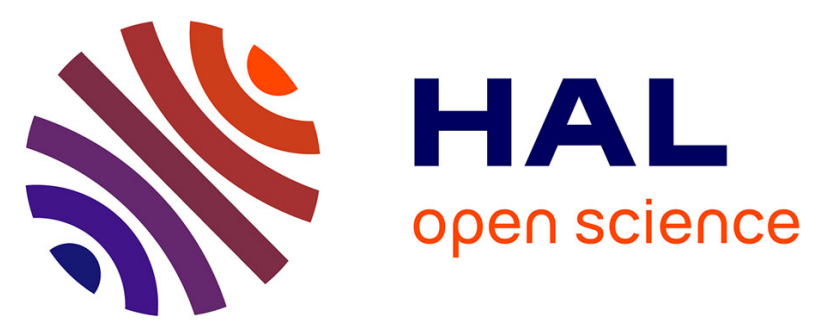

\title{
Direct laser fabrication process with coaxial powder projection of 316L steel. Geometrical characteristics and microstructure characterization of wall structures
}

Hussam El Cheikh, Bruno Courant, Samuel Branchu, Xiaowei Huang, Jean-Yves Hascoët, Ronald Guillén

\section{To cite this version:}

Hussam El Cheikh, Bruno Courant, Samuel Branchu, Xiaowei Huang, Jean-Yves Hascoët, et al.. Direct laser fabrication process with coaxial powder projection of 316L steel. Geometrical characteristics and microstructure characterization of wall structures. Optics and Lasers in Engineering, 2012, 50 (12), pp.1779-1784. 10.1016/j.optlaseng.2012.07.002 . hal-01006750

\author{
HAL Id: hal-01006750 \\ https://hal.science/hal-01006750
}

Submitted on 12 Dec 2018

HAL is a multi-disciplinary open access archive for the deposit and dissemination of scientific research documents, whether they are published or not. The documents may come from teaching and research institutions in France or abroad, or from public or private research centers.
L'archive ouverte pluridisciplinaire HAL, est destinée au dépôt et à la diffusion de documents scientifiques de niveau recherche, publiés ou non, émanant des établissements d'enseignement et de recherche français ou étrangers, des laboratoires publics ou privés. 


\title{
Direct Laser Fabrication process with coaxial powder projection of 316L steel. Geometrical characteristics and microstructure characterization of wall structures
}

\author{
Hussam El Cheikh ${ }^{\mathrm{a}, *}$, Bruno Courant ${ }^{\mathrm{a}}$, Samuel Branchu ${ }^{\mathrm{a}}$, Xiaowei Huang ${ }^{\mathrm{c}}$, Jean-Yves Hascoët ${ }^{\mathrm{b}}$, \\ Ronald Guillén ${ }^{\mathrm{a}}$ \\ a LUNAM Université, Université de Nantes, Ecole Centrale de Nantes, Institut de Recherche en Génie Civil et Mécanique UMR CNRS 6183, France \\ ${ }^{\mathrm{b}}$ Institut de recherche en Communications et en Cybernétique de Nantes (IRCCyN) UMR CNRS 6597, France \\ ${ }^{\mathrm{c}}$ Arts et Métiers ParisTech, Angers, France
}

\begin{abstract}
Direct Laser Fabrication is a promising manufacturing technology. A moving laser beam heats a coaxially delivered powder in a gas jet through nozzle in order to fabricate an end-use part directly. The clad geometry is an important process characteristic. In this work, different velocities and different laser shift-distances between two successive layers are used to build walls. For each condition, 1, 3, 5 and 10 layers walls are analyzed, showing the domain of a success and optimal construction. A relationship between the process parameters and the wall height is obtained with a good correlation. In addition a linear relationship relates the wall height to the number of layers. Columnar dendrites are observed on the bottom laser clad and equiaxed grains on the top one. Microhardness measurements show a homogeneous microhardness in each layer but a higher microhardness in the first one.
\end{abstract}

\section{Introduction}

Direct Laser Fabrication (DLF) is a new rapid manufacturing process based on laser cladding and derived from welding, microwelding and laser technologies [1-4]. A power laser beam heats powder grains delivered from a coaxial nozzle system. The material is deposited in a molten state, layer by layer onto the previous solidified layer. This technique brings several advantages over conventional fabrication techniques. These advantages include faster processing speed, no requirement of tooling, ability to fabricate complex shapes and obtaining of metastable microstructure/composition [5].

Many works have been proposed to simulate the thermal field induced in a material heated by a moving laser beam during the 80s and 90s [6-8]. In the 2000s many authors used these models to simulate the DLF process. Picasso et al. [9] developed a simple geometrical model for laser cladding, their model allows to calculate the laser beam velocity and the powder feed rate for a specified laser power, beam diameter and clad height however the powder was deposited on the substrate. Oliveira et al. [10]

\footnotetext{
* Corresponding author. Tel.: +33 240172619; fax: +33 240172618.

E-mail address: hussam-elcheikh@hotmail.fr (H. El Cheikh).
}

present a theoretical and experimental study of the coaxial laser cladding process to understand the basic concepts of the process and the relationships between the main coaxial laser cladding parameters and geometrical characteristics of an individual laser track. Toyserkani et al. [11,12] use a transient three-dimensional finite element modeling, to show the relationship between the laser track geometry and experimental parameters. The more the laser beam velocity decreases, or the more the powder feed rate and the laser pulse energy increase, the more the clad height increases. Peyre et al. [13] link the process parameters to the clad height and the material conductivity. They take into account the moving interface with a specific function allowing the conductivity front to move simultaneously with the moving laser source. Cheikh et al. [14,15] have shown that the clad geometry is not controlled by the powder distribution into the jet. They propose a phenomenological circular form model taking into account the surface tension forces between the protecting gases, the laser clad material and the substrate material to predict all their experimental results concerning $316 \mathrm{~L}$ clad on low carbon substrate. Majumdar et al. [16] studied the influence of laser parameters on the microstructure at the surface and the interface between the successive layers of AISI 316L stainless steel by direct laser deposition technique using a continuous wave diode. Zhang et al. [17] investigated laser cladding forming for Ni-based 
tungsten carbides (WC) thin walls, including the phase constitution, the microstructure and the microhardness. Li et al. [18] researched on the effect of processing parameters, such as the powder injection point position, the laser power output, the scanning velocity, the laser spot diameter, etc., on the forming characterizations, for instance the height and width of single layer clad through laser rapid forming experiments on 316L and Ni20 components. Murr et al. [19] compared the microstructure and mechanical behavior of simple product geometries produced by layered manufacturing using the electron beam melting (EBM) process and the selective laser melting (SLM) process with Ti-6Al$4 \mathrm{~V}$ conventional wrought and cast products characteristics.

Although lots of experiments with different materials have been carried out to investigate microstructure characteristics, microhardness, residual stresses distributions independently in the components fabricated by DLF, there are few detailed reports focused on the quality of the wall according to the processing parameters. However, the single clad geometry is important to control the forming procedure accurately and build a component [14]. Besides, it will be meaningful to integrate multi-layer geometry predictions with microstructures characteristics and mechanical behaviors identification, for instance microhardness, which are beneficial for the precise fabrication of complex components and offer bases for numerical simulation of the DLF process.

In this paper, walls height is related to the number of layers and the surface state quality is discussed. The fabrication time is taken into account in order to find the best parameters. The microstructure morphology and microhardness measurements are analyzed.

\section{Experimental conditions}

In this work a coaxial nozzle is associated with a 5 axes machine and a $700 \mathrm{~W}$ fiber laser for which diameter is $150 \mu \mathrm{m}$. The laser type is "YLS-4000-ST2 (Ytterbium Fiber Laser System)" and the wave length is $1070-1080 \mu \mathrm{m}$. A carrier gas (Ar) flow, fixed at $3 \mathrm{l} / \mathrm{min}$, carries the powder while a secondary gas (Ar) flow, fixed at $5 \mathrm{l} / \mathrm{min}$, shapes the powder stream. The laser beam is focused on the substrate surface while the working distance between the nozzle and the focus plan remains constant at $5 \mathrm{~mm}$. In this study a $316 \mathrm{~L}$ powder is used to fabricate the experimental walls, with particles size between 45 and $90 \mu \mathrm{m}$. The used substrate is a low carbon steel.

Choosing the three parameters $P, Q_{m}$ and $V$ results in obtaining a specific geometry. By setting the laser power $P$ and the powder feed rate $Q_{m}$ and by varying the laser speed, one can obtain a wild

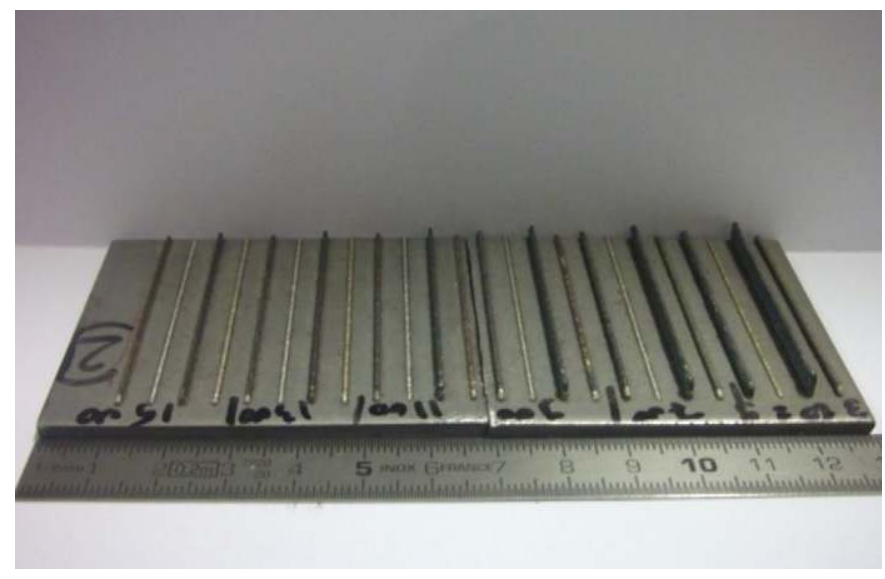

Fig. 1. Image showing multilayer's depositions on a low carbon steel substrate. range of laser clad geometries. From our experience, the multilayer tracks are produced with constant power $P$ and powder feed rate $Q_{m}$ corresponding respectively to $280 \mathrm{~W}$ and $0.05 \mathrm{~g} / \mathrm{s}$. On the other hand the scan speed $V$ varies from 500 to $1500 \mathrm{~mm} / \mathrm{min}$ with a $200 \mathrm{~mm} / \mathrm{min}$ increment, three different vertical laser shiftdistances $0.20,0.25$ and $0.30 \mathrm{~mm}$ are experimented and for each combination four parts are built with respectively $1,3,5$, and 10 layers. Fig. 1 shows the geometrical good quality and the sharpness of the most part of the built walls.

The microstructure characterization is carried out by an Optical Microscopy and a Scanning Electron Microscopy. The microhardness is measured with a hardness testing machine MVK-H1.

\section{Results and discussions}

\subsection{Geometric characterization}

The height measurements $(H)$ are shown in Table 1 for different laser shift-distances and velocities. One laser clad height with our equipment is about few hundred of micrometers. The three different vertical laser shift distances $0.20,0.025$ and $0.30 \mathrm{~mm}$ have been chosen to test the robustness of the process and the influence of this parameter on a wall including up to ten layers.

Fig. 2 shows the observed cross sections for the different velocities and in case of 1 and 10 layers. We can notice that the velocity increase improves the wall quality. For the slowest velocity of $500 \mathrm{~mm} / \mathrm{min}$, the single layer cross section shows a quasi complete circular form due to the accumulation of powder and according to the tensile forces equilibrium. The wall cross section for this velocity shows a very bad surface state.

Dashed lines, in Fig. 2b, show an idealized rectangular wall in comparison with the real one. Of course this perfect geometry cannot be obtained with our process but it can be used as a model.

Fig. 3 compares the ratio between the cross sections surfaces of the real wall and the ideal one for the six different velocities. One can see, in Figs. 2 and 3, that at highest scanning speeds, the geometry of multilayer walls is closed to the ideal rectangular shape and so the wall geometry is improved. Cross sections (d, e and f), shown in Fig. 2, are more or less similar in shape. This is also obvious from Fig. 3, where saturation clearly appears for highest velocities. The highest speed leads to the highest ratio. In case of $0.20 \mathrm{~mm}$ laser shift, saturation occurs when the laser speed reaches $1100 \mathrm{~mm} / \mathrm{min}$ and in the two other cases when it reaches $900 \mathrm{~mm} / \mathrm{min}$. In case of a too low speed, the wall quality is really bad (case a).

Table 1

Height of the laser tracks for different velocities and different vertical laser shifts (mm).

\begin{tabular}{llllllll}
\hline Laser velocity & $(\mathbf{m m} / \mathbf{m i n})$ & $\mathbf{5 0 0}$ & $\mathbf{7 0 0}$ & $\mathbf{9 0 0}$ & $\mathbf{1 1 0 0}$ & $\mathbf{1 3 0 0}$ & $\mathbf{1 5 0 0}$ \\
\hline $\boldsymbol{h}=\mathbf{0 . 2 0} \mathbf{~ m m}$ & 1 layer & 0.516 & 0.356 & 0.227 & 0.217 & 0.197 & 0.2 \\
& 3 layers & 1.2 & 0.932 & 0.64 & 0.6 & 0.533 & 0.46 \\
& 5 layers & 2.065 & 1.632 & 1.266 & 1.089 & 0.824 & 0.796 \\
$\boldsymbol{h}=\mathbf{0 . 2 5} \mathbf{~ m m}$ & 10 layers & 3.9 & 3.245 & 2.728 & 2.161 & 1.89 & 1.619 \\
& 1 & 0.523 & 0.368 & 0.33 & 0.253 & 0.227 & 0.192 \\
& 3 & 1.282 & 0.898 & - & 0.617 & 0.555 & 0.51 \\
$\boldsymbol{h}=\mathbf{0 . 3 0} \mathbf{~ m m}$ & 5 & 2.119 & 1.626 & 1.231 & 1.057 & 0.92 & 0.824 \\
& 10 & 4.3 & 3.3 & 2.65 & 2.1 & 1.9 & 1.55 \\
& 1 & 0.543 & 0.38 & 0.281 & 0.28 & 0.215 & 0.221 \\
& 5 & 1.418 & 0.976 & 0.761 & 0.667 & 0.565 & 0.5132 \\
& 10 & 2.218 & 1.684 & 1.215 & 0.998 & 0.904 & 0.762 \\
& 4.27 & 3.318 & 2.734 & 2.26 & 1.737 & 1.6 \\
\hline
\end{tabular}



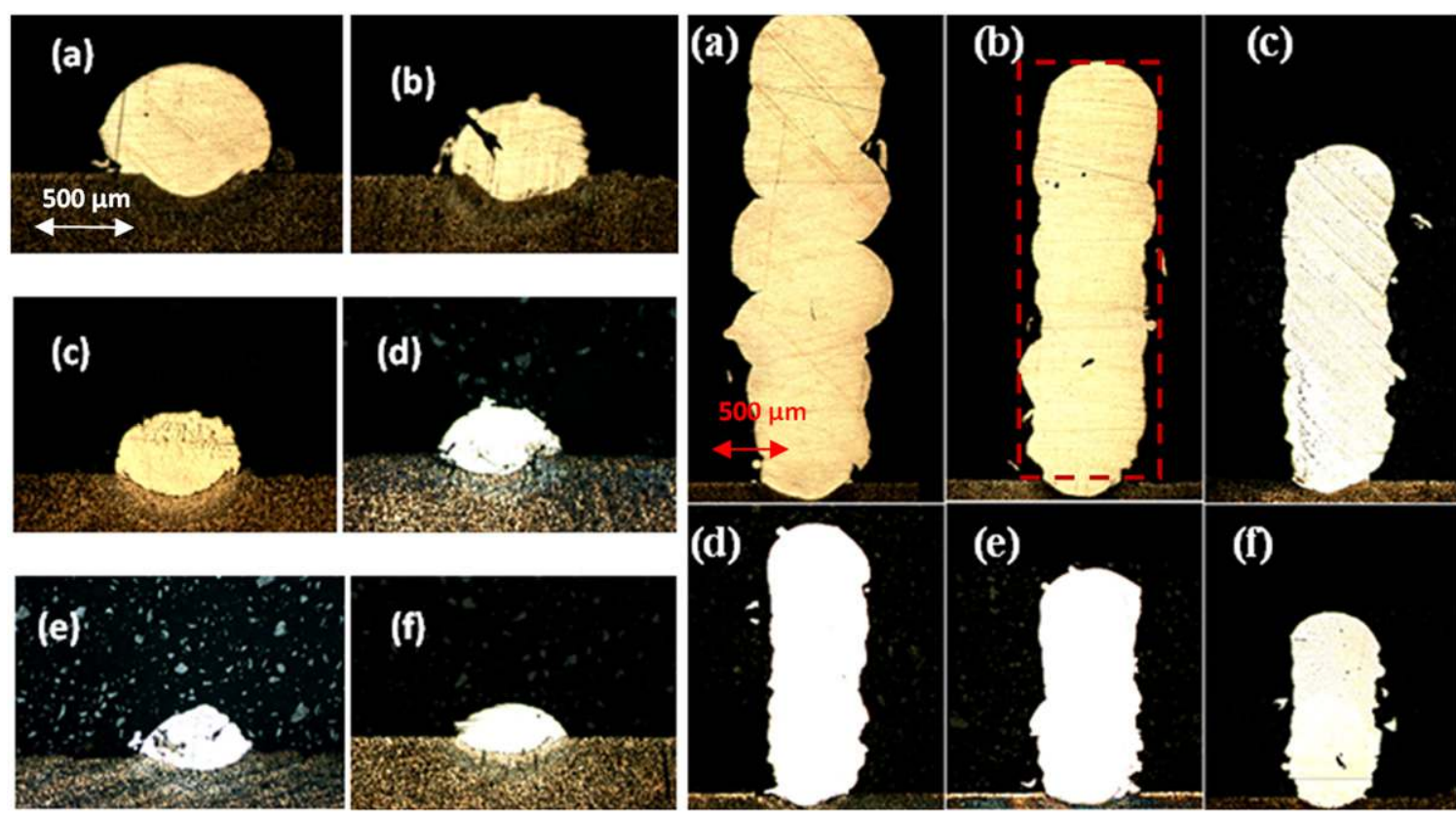

(e)

Fig. 2. Cross sections of laser tracks in case of 1 and 10 layers with six different velocities (a) $500 \mathrm{~mm} / \mathrm{min}$, (b) $700 \mathrm{~min} / \mathrm{min}$, (c) $900 \mathrm{~mm} / \mathrm{min}$, (d) $1100 \mathrm{~min} / \mathrm{min}$, (e) $1300 \mathrm{~mm} / \mathrm{min}$ and (f) $1500 \mathrm{~mm} / \mathrm{min}$.

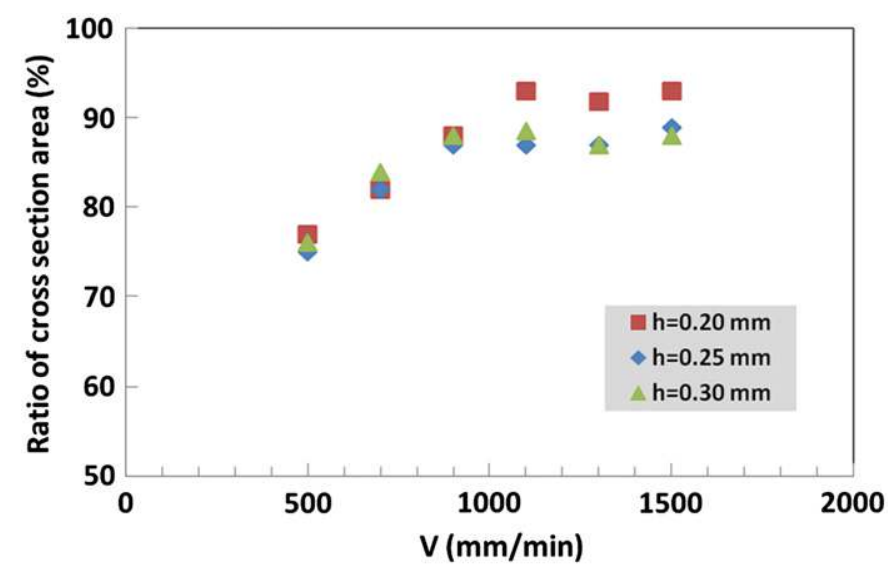

Fig. 3. Ratio of the "real" and "ideal" wall cross section area for the six different velocities and the three different laser shifts.

Fig. 4 shows the relationship between the measured height and the laser velocity for a vertical laser shift-distance fixed to $0.25 \mathrm{~mm}$. A linear dependency between the measured height and the number of layers is shown; we can write that $H_{n}=n \times H_{m}$ where $n$ is the number of deposit layers.

Equations for the lowest and the highest velocities are shown in Fig. 4. $H_{n}=0.395 \times n$ for a velocity of $500 \mathrm{~mm} / \mathrm{min}$, with a correlation coefficient $R^{2}=0.096, H_{n}=0.161 \times n$ for the velocity of $1500 \mathrm{~mm} / \mathrm{min}$, with a correlation coefficient $R^{2}=0.998$.

The three different vertical laser shift-distances tested do not show meaningful differences on the walls' heights. A $100 \mu \mathrm{m}$ variation in the laser shift is not critical to build a wall including up to ten layers. In case of single laser tracks, the laser clad height varies from 0.192 to $0.543 \mathrm{~mm}$. From Fig. 3, it can be deduced that a good quality is obtained when the speed is equal or greater than $900 \mathrm{~mm} / \mathrm{min}$. One can notice that the clad height, in these conditions, is between 0.330 and $0.192 \mathrm{~mm}$ which is very close to the selected laser shifts $0.20,0.25$ and $0.30 \mathrm{~mm}$. In case of $0.20 \mathrm{~mm}$ laser shift, saturation occurs for a laser speed reaching $1100 \mathrm{~mm} / \mathrm{min}$. In these conditions, the ten layers wall measures

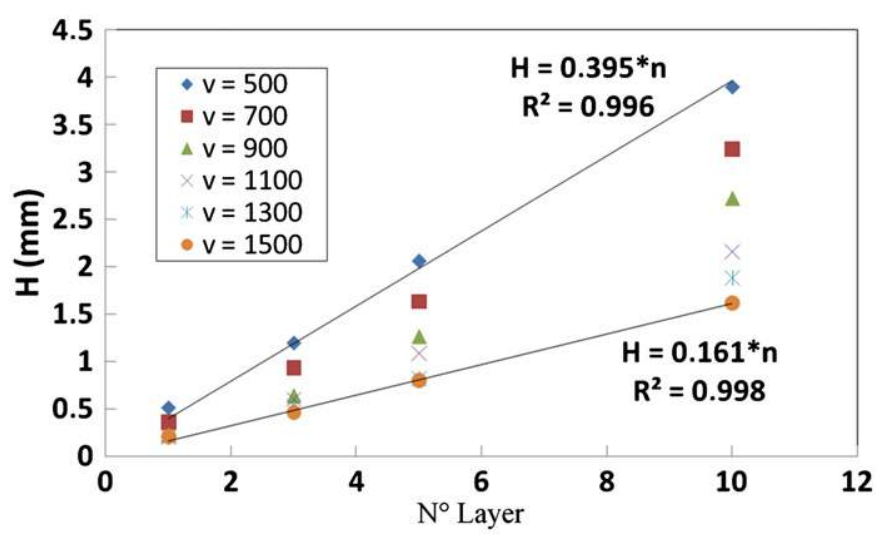

Fig. 4. Relationship between the walls measured height and the number of deposit layers in case of six different velocities. The laser power is $180 \mathrm{~W}$, the powder feeding rate $0.05 \mathrm{~g} / \mathrm{s}$ and the laser vertical shift between two layers is fixed at $0.25 \mathrm{~mm}$.

$2.161 \mathrm{~mm}$ and so the mean value of each layer is $0.216 \mathrm{~mm}$ very close to the chosen laser shift. In case of 0.25 and $0.30 \mathrm{~mm}$ laser shifts, saturation occurs earlier for a laser speed of $900 \mathrm{~mm} / \mathrm{min}$, the mean value for each layer being respectively 0.265 and $0.273 \mathrm{~mm}$. In all cases, the wall quality is still very good when the speed increases even if the mean value for each layer becomes very low in comparison with the laser shift. The lower laser shift leads to the better wall quality criterion with more than $90 \%$. The wall quality is then improved by the good adequacy between the laser shift and the clad height.

The height is related to the process parameters with the following equation [14]:

$$
H_{1}=0.0074\left(P^{1 / 3} Q_{m}^{3 / 4} V^{-1}\right)+0.046
$$

So, with a constant laser power and powder mass flow, the height of a wall with $n$ layers is related to the velocity by the equation:

$H_{n}=\frac{K_{1}}{V}+K_{2}$ 


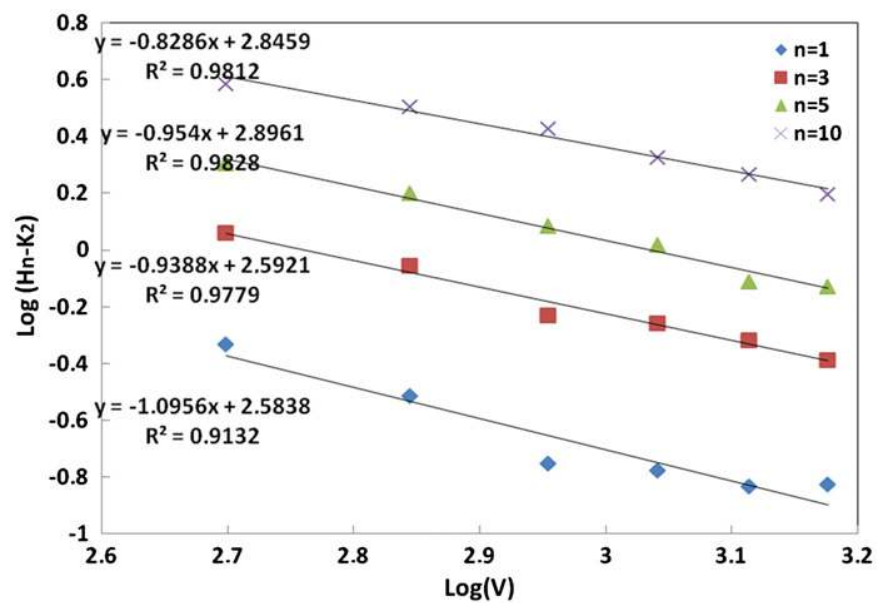

Fig. 5. Log representation of the wall height versus laser velocity in case of 1,3 , 5 and 10 deposit layers.

where $K_{1}$ is a constant including the process parameters power $P$ and mass flow $Q_{m}$. $K_{2}$ is a constant equal to 0.046 .

The logarithmic equation is given by

$\log \left(H_{n}-K_{2}\right)=-\log (V)+\log \left(K_{1}\right)$

In Fig. $5, \log \left(H_{n}-K_{2}\right)$ is drawn with respect to $\log (V)$.

Numerical values of this logarithmic relationship for a vertical laser shift of $0.25 \mathrm{~mm}$ and in case of 1, 3, 5 and 10 deposit layers are exposed in Fig. 5.

This parametric equation is well verified for whatever the number of layers is. The smallest slope $(-0.8286)$ is observed for the walls with ten layers and the highest one for the one layer clad with -1.0956 . In all cases the slope is near from the expected one which is $(-1)$.

The correlation coefficients $(0.9132,0.9779,0.9828$ and 0.9812) show a good agreement with the expected linear relationship.

The time $t_{1}$ needed to fabricate a 10 layers wall of length $l$ at a constant velocity $V$ is given by $t_{1}=(10 \times l) / V$. In one hand the highest velocity leads to the shorter time but in another hand, the height is smaller. To compare the different walls, it is more convenient to compare the time to fabricate a wall of a given height.

For the time " $t$ ", we can build $\left(n^{\prime}\right)$ layers with another velocity $\left(\mathrm{V}^{\prime}\right)$, and $t=n^{\prime} \times l / V^{\prime}$. The expected height of the wall is then given by $\left(n^{\prime} \times H_{m, V}\right)$, where $H_{m, V}$ is the mean height for one laser clad obtained with the velocity $V^{\prime}$. Fig. 6 shows the expected height of walls for the same time $(t)$ of fabrication. It shows that the velocity increase leads to a higher wall.

In conclusion, the velocity increase improves the wall quality and in addition leads to a shorter time to fabricate a wall of a given height. It might be noticed that the highest speed is not always the one for which the laser shift is equal to the laser clad height.

\subsection{Microstructures}

Microstructure is a very important characteristic of the laser deposit because it has a strong impact on the mechanical properties. A study of the microstructure shows different grains morphologies shown in Fig. 7. Almost, everywhere in the walls, columnar dendrites can be seen. Their direction growth is perpendicular to the solidification front and so depends on the local solidification conditions. The laser clad microstructure

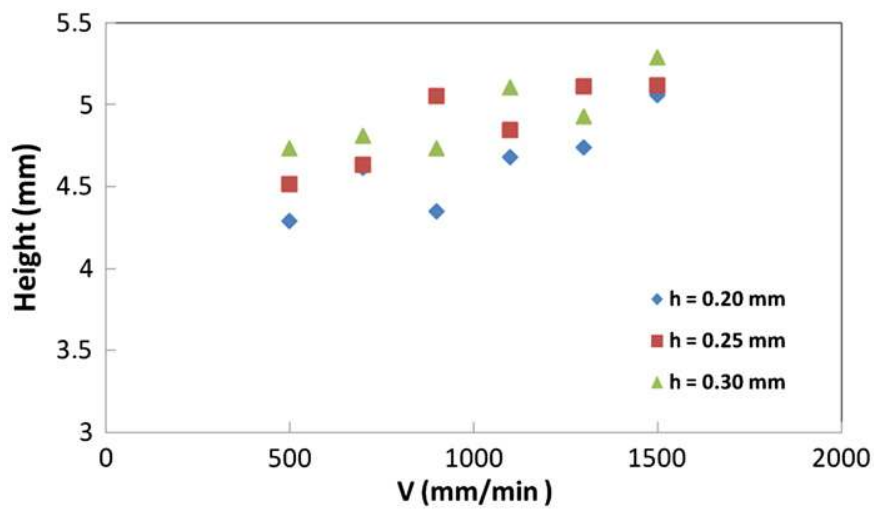

Fig. 6. Walls height for different velocities during the same time $(t)$ of fabrication.

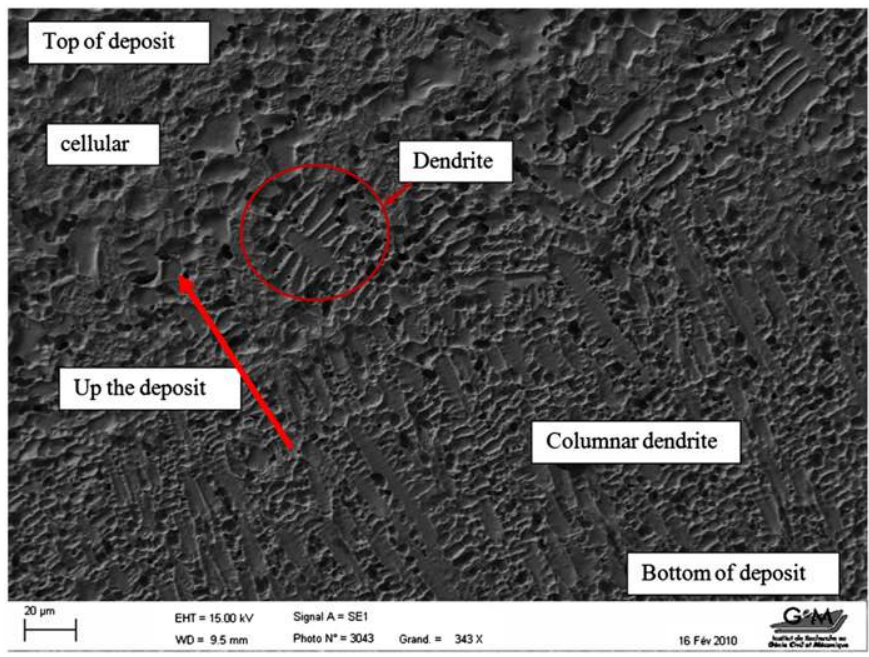

Fig. 7. Cellular growth and dendrite grain growth on the bottom and the top of a component observed with SEM.

morphology is affected by the ratio between the $\left(g_{T}\right)$ temperature gradient and the solidification velocity $\left(V_{s}\right) . V_{s}$ is the projection of the laser speed $V$ on the normal of the solidification front. If this ratio $\left(g_{T} / V_{S}\right)$ is high the solidification front is stable and otherwise instability occurs. In the bottom region of the laser clad, $V_{s}$ is small because the laser speed $V$ is nearly perpendicular to the normal of the solidification front. So the quotient is high and a columnar dendrite growth is observed. In the top part of the clad, $V_{s}$ reaches its maximum value which is equal to the laser speed $V$ and the quotient $\left(g_{T} / V_{s}\right)$ becomes lower. Therefore, the solidification front instabilities lead to the growth of short dendrites. Specific cooling conditions, due to the heat exchange by convection with the protecting gas, could also play a part in the emergence of the front instabilities. Fig. 7 has been taken near the top of the last laser clad in order to illustrate these different morphologies. Progressively the microstructure varies from columnar dendrites to short dendrites (about $10 \mu \mathrm{m}$ grains length) near the wall surface.

Fig. 8 shows a longitudinal cross-section for a multi layers laser wall observed with an optical microscope (a) and for a detailed zone with SEM (b). Fig. 8a presents the solidification front of the molten pool and the growth grains direction. The top of each laser track is melted again by the next layer and so the upper dendrite zone disappears. Fig. 8b shows a detail of the 

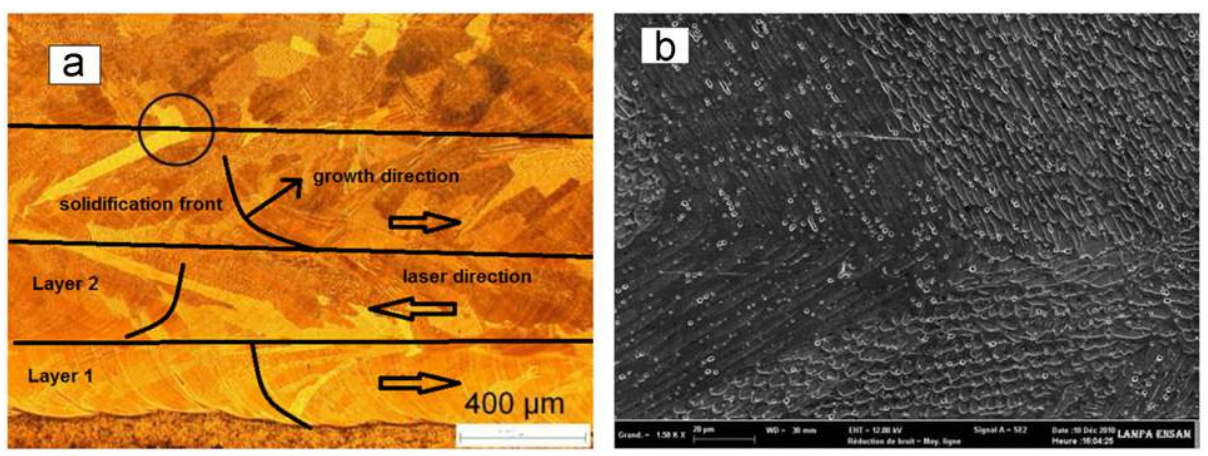

Fig. 8. Longitudinal cross-section of multilayer track, observed with an optical microscope (a) and SEM for the detailed zone, image (b).

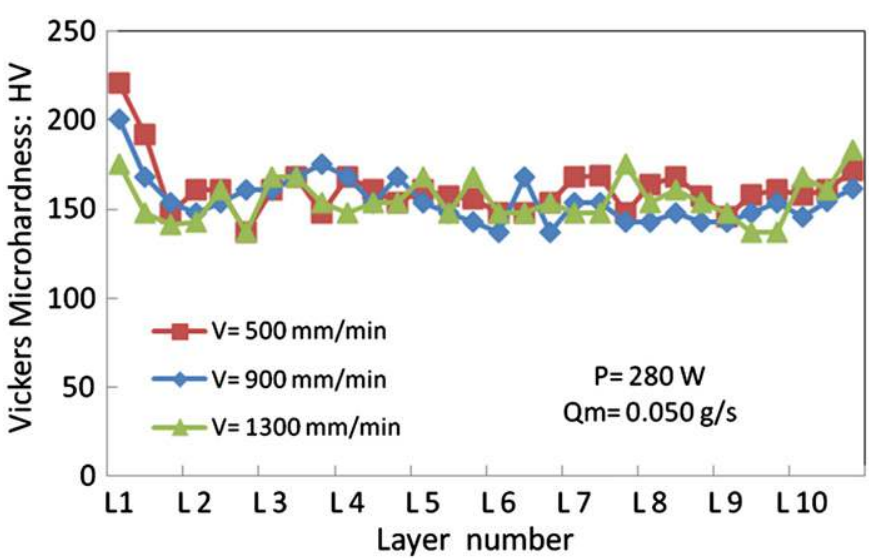

Fig. 9. Microhardness versus layers number for three different velocities.

junction between two successive layers (the circular zone in Fig. 8a) in which grains orientation is perpendicular between two successive layers.

\subsection{Microhardness}

Microhardness analysis of the single layer tracks shows that the average microhardness varies from 130 to $230 \mathrm{HV}$. In each layer three measurements are made, located near the bottom interface, in the middle and near the top interface. The microhardness evolution, layer by layer, for each laser scanning speed $500 \mathrm{~mm} / \mathrm{min}, 900 \mathrm{~mm} / \mathrm{min}$ and $1300 \mathrm{~mm} / \mathrm{min}\left(\mathrm{P}=280 \mathrm{~W}, Q_{m}=3 \mathrm{~g} / \mathrm{min}\right.$, Inter pass distance $=$ $0.25 \mathrm{~mm}$ ) is presented in Fig. 9. The horizontal axis represents the layer number and the vertical one, the corresponding Vickers microhardness. The microhardness is bigger in the first layer, this fact is due to the dilution between the added material (316L) and the substrate material (low carbon steel).

\section{Summary and conclusion}

This study focuses on the prediction of the height and the surface state quality of walls fabricated by laser direct fabrication process. Multi layers tracks are realized with different values of the process parameters: laser speed $V$ and vertical laser shift $h$. A linear relationship between the height and the number of layers is observed, whatever the velocity or the laser shift. These relationships can be used to predict the wall height from the process parameters. In order to find the best parameters, the fabrication time is taken into account. The quality of the fabricated walls is discussed and related to the process parameters.
This study shows that, when the velocity increases, it leads to layer thickness close or inferior to the chosen vertical laser shift and the surface state is improved. A low laser shift combined with a high laser speed seems to be the better choice to optimize the wall quality and the time of fabrication. The microstructure study shows columnar dendrites grains with different growth directions, and at the top of the component, short dendrites. Microhardness measurements show a homogeneous microhardness in each layer but a higher one in the first layer because of the dilution part coming from the low carbon steel substrate. For a functional part, this non suitable layer can be removed when the part construction is finished.

\section{Acknowledgments}

Thanks to Gilles Carabin for his mastery of the machine and to Marie-José Moya for the proofreading and English corrections.

\section{References}

[1] Levy GN, Schindel R, Kruth JP. Rapid manufacturing and rapid tooling with layer manufacturing (LM) technologies, state of the art and future perspectives. RP Ann-Manuf Technol 2003;52(2):589-609.

[2] Steen WM. Laser material processing. Berlin: Springer; 1991.

[3] Courant B, Hantzpergue JJ, Benayoun S. Surface treatment of titanium by laser irradiation to improve resistance to dry-sliding friction. Wear 1999;236(1-2): 39-46.

[4] Courant B, Hantzpergue JJ, Avril L, Benayoun S. Structure and hardness of titanium surfaces carburized by pulsed laser melting with graphite addition. J Mater Process Technol 2005;160:374-81.

[5] Laeng J, Stewart JG, Liou FW. Int J Prod Res 2000;38:3973-96.

[6] Courant B, Hantzpergue JJ, Benayoun S, L'huillier JP. Melting and solidification processes in a moving graphite-covered titanium surface subjected to multipulsed laser irradiation. J Phys D: Appl Phys 2001;34:1437-46.

[7] Rappaz M. Les données générales de la simulation dans le traitement laserLaser de puissance et traitements de matériaux. A.B. Vannes, Presses Polytechniques et Universitaires Romandes; 1991. pp. 375-401.

[8] Hsu HC, Chakravortys S, Mehrabian R. Rapid melting and Solidification of a surface Layer. Metall Mater Trans B 1978;9:221-9.

[9] Picasso M, Marsden CF, Wagniere JD, Frenk A, Rappaz M. A simple but realistic model for laser cladding. Metall Mater Trans B 1994;25:281-91.

[10] de Oliveira U, Ocelık V, De Hosson JThM. Analysis of coaxial laser cladding processing conditions. Surf Coat Technol 2005;197:127-36.

[11] Toyserkani E, Khajepour A, Corbin S. 3-D finite element modeling of laser cladding by powder deposition: effects of powder feed rate and travel speed on the process. J Laser Appl 2004;15(3):153-60.

[12] Toyserkani E, Khajepour A, Corbin S. 3-D finite element modeling of laser cladding by powder injection: effects of laser pulse shaping on the process. Opt Lasers Eng 2004;41:849-67.

[13] Peyre P, Aubry P, Fabbro R, Neveu R, Longuet A. Analytical and numerical moddeling of the direct metal deposition laser process. J Phys D: Appl Phys 2008;41:025403-13.

[14] El Cheikh H, Courant B, Branchu S, Hascoët J-Y, Guillén R. Analysis and prediction of single laser tracks geometrical characteristics in coaxial laser cladding process. Opt Laser Eng 2012;50(3):413-22.

[15] El Cheikh H, Courant B, Hascoët J-Y, Guillén R. Prediction and analytical description of the single laser track geometry in direct laser fabrication from 
process parameters and energy balance reasoning. J Mater Process 2012;212: 1832-9.

[16] Majumdar JD, Pinkerton A, Liu Z, Manna I, Li L. Microstructure characterization and process optimization of laser assisted rapid fabrication of $316 \mathrm{~L}$ stainless steel. Appl Surf Sci 2005;247:320-7.

[17] Zhang Yonghong, Xi Mingzhe, Gao Shiyou, Shi Likai. Characterization of laser direct deposited metallic parts. J Mater Process Tech 2003;142:582-5.
[18] Li Yanmin, Yang Haiou, Lin Xin, Huang Weidong, Li Jianguo, Zhou Yaohe. The influences of processing parameters on forming characterizations during laser rapid forming. Mater Sci Eng A 2003;360(1-2):18-25.

[19] Murr LE, Quinones SA, Gaytan SM, Lopez MJ, Rodela A, Martinez EY, Hernandez DH, Martinez E, Medina F, Wicker RB. Microstructure and mechanical behavior of Ti-6Al-4V produced by rapid-layer manufacturing, for biomedical applications. J Mech Behav Biomed Mater 2009;2(1):20-32. 